\title{
The impact of filter bed depth and solids loading using a multimedia filter
}

\author{
Philani Ncube, Marc Pidou, Peter Jarvis ${ }^{+}$ \\ Cranfield Water Science Institute, Cranfield University, Cranfield, MK43 0AL, UK \\ +corresponding author: p.jarvis@cranfield.ac.uk
}

\begin{abstract}
Design and operation of tertiary wastewater filters is not always well understood because of the inherent complexities of the wastewater matrix. Here, comparison of single, dual, triple and quadruple media (anthracite, flint, alumina and magnetite) filters were made to understand how the depth, media type and solids concentration influenced performance. The filter was improved by making the media deeper, however the top $0.1 \mathrm{~m}$ of the filter retained the most solids. Additional layers of filter materials from single, dual, triple to quadruple improved the filter performance for the same depth of filter bed.
\end{abstract}

Keywords Solids concentration; wastewater; depth filtration; multi-media; headloss 


\section{Introduction}

More stringent discharge requirements for treated wastewater has become ever more important to improve water quality. In addition, the growing demand for water reuse in water stressed regions has driven the need for tertiary treatment of wastewater [1-3]. There are many different forms of tertiary treatment of wastewater, of which granular media filtration is a common choice due to its simplicity and its historical performance in drinking water treatment systems [3-6]. However, the process design of granular filters is challenging as it involves a trade-off between various factors, such as the type and size of the filter media, the depth of media, the hydraulic loading rate, the headloss through the filter bed, the backwash hydraulics as well as the solids loading rate [7-9]. Significant benefits in particle removal and headloss can be realised through using new filters designs. This includes application of new filter media such as compressible crumb rubber $[10,11]$ and multi-media filters that utilise up to four different media of different particle size and density [12].

Many design engineers recommend a rule-of-thumb empirical guideline for filter design stipulating the ratio of the filter depth to media size $\left(L / d_{m}\right)$ being between 1000-1200 [7-9. 13]. Drinking water filters designed by this guideline have generally operated reliably and applications in wastewater have followed [8-9]. However, wastewater has a higher solids concentration and the quality of discharged effluent is usually lower than that required for drinking water, hence wastewater tertiary filters have historically used a coarser media to facilitate feasible operation. Using novel configurations with media of different size and density can overcome some of these challenges. However, there is limited information on how existing design guidance fits with application to multi-media filters.

Lawler and Nason [8] examined a number of operational full-scale filters used for water and wastewater filtration, and demonstrated that these filters had $L / d_{m}$ ratios ranging from 850 to 
1517. In this research, they set-out to introduce theory into filter design by using the Yao et al. [13] model of the efficiency of a packed bed and empirically determined a collection efficiency of $25 \%$ for particles of minimum removal (1-2 $\mu \mathrm{m}$ in diameter) [8]. A filter coefficient of $25 \%$ collection efficiency was then used as a further basis for filter depth design [8]. The Lawler and Nason [8] design criterion therefore has a theoretical basis in that it considers the temperature and filtration velocity parameters that are intrinsic to the contact efficiency $(\eta)$ calculated [14].

The influent solids concentration is also known to influence the performance of depth filtration $[1-2 ; 15]$. However, this aspect has received limited attention in wastewater filtration. From the few studies that have been carried out mixed observations have been seen in filter performance as influent solids concentration increases [16]. For example, in one study, the effluent quality was found to be dependent on the influent solid concentration; the filters achieved a $70 \%$ solid removal for an influent solid concentration of $35-40 \mathrm{mgL}^{-1}$ and a $32 \%$ solid removal for an influent solid concentration of $95 \mathrm{mgL}^{-1}$ [16]. Hamoda et al. [1] reported no significant change in effluent quality with changing influent concentration while Dawda et al. [17] concluded that the variability of influent concentration on a full scale experiment complicated the interpretation of filter performance studies such that different filter runs could not be objectively compared. Tebbutt [4] concluded that low solids removal in filtration tests were due to low concentrations of wastewater of $10-20 \mathrm{mgL}^{-1}$ in the suspended solids. It is therefore important to establish stronger relationships between solids loading onto filtration systems and filter performance with respect to overall removal and specific mass deposits of solid particles.

There is, therefore, uncertainty regarding the filter depth design and the effect of the influent suspension concentration on the output quality. The aim of this study was to determine how the filter depth, media type and the filter influent concentration influenced the effluent quality 
particle removal characteristics and the headloss development using mono, dual, triple and quadruple filter media configurations treating wastewater secondary effluent. Separation of the filter layers is achieved by using large media of low density and smaller media of high density such that the bed stratifies and segregates following backwash.

\section{Materials and Methods}

\section{Filtration tests}

The investigation was carried out using a pilot plant located at a small sewage treatment works (STWs) in the United Kingdom filtering real secondary treated wastewater effluent. The works treats $450 \mathrm{~m}^{3} \mathrm{~d}^{-1}$ of municipal wastewater using preliminary screening and grit removal, primary sedimentation, alum dosing, trickling filters and secondary sedimentation. Secondary effluent from the STWs discharge well was pumped to a mixed holding tank from where the feed was transferred to the filter rig (more detail in Ncube et al. [12]). The quadruple media pressure filter design was adapted using the same media layers as used in a commercial filter system (FilterClear, BluewaterBio, UK). In pressure filters, pump pressure provides the head in the same way as the water head does in gravity filters.

Each column was loaded with a different media at a predetermined depth in the range 0.02 $0.32 \mathrm{~m}$. The media were characterised by their Effective Size (ES), defined as the $\mathrm{d}_{10}$ particle size from sieve analysis [18]; Uniformity Coefficient, defined as the ratio of the $\mathrm{d}_{60}$ to the $\mathrm{d}_{10}$ particle size as determined by sieve analysis [18]: Clean Bed Porosity $\left(\varepsilon_{0}\right)$, defined as the volume proportion of all void spaces to the total volume of the bed [19]; and Sphericity $(\psi)$, defined as the surface area of a sphere of the same volume as the particle divided by the actual surface area of the particle [20]. The media specifications were as follows: anthracite 
$\left(\mathrm{ES}=1.12 \mathrm{~mm}, \mathrm{UC}=1.49, \varepsilon_{0}=0.51, \psi=0.54\right)$, flint $\left(\mathrm{ES}=0.55 \mathrm{~mm}, \mathrm{UC}=1.42, \varepsilon_{0}=0.52, \psi=\right.$ $0.64)$, alumina $\left(\mathrm{ES}=0.58 \mathrm{~mm}, \mathrm{UC}=1.13, \varepsilon_{0}=0.55, \psi=0.63\right)$ and magnetite $(\mathrm{ES}=0.26 \mathrm{~mm}$, $\left.\mathrm{UC}=1.54, \varepsilon_{0}=0.47, \psi=0.84\right)$ respectively. A standard method, American Society for Testing and Materials (ASTM) C136-2006) was used to obtain the media PSD and uniformity coefficient [19]. The loose bed porosity $\varepsilon_{0}$ was determined by method ASTM C1252-2006 and the media sphericity $\psi$ was determined by calculations based on clean bed headloss measurement and the Kozeny-Carman equation [21].

The filters were composed of clear acrylic Perspex columns of depth $0.7 \mathrm{~m}$ with an internal diameter of $0.074 \mathrm{~m}$, resulting in a cross sectional area of $0.0043 \mathrm{~m}^{2}$ (Figure S1). Online instruments for flowrate, pressure and turbidity were connected to the filter rig and the output analogue signals were logged onto a laptop by an analogue-digital data logger. The columns were fitted with pressure transducers (PN2026, IMF Electronic Ltd, Germany) to measure the pressure drop across the filter bed. As a result of variable readings observed for low headloss $(<0.4$ Bar $)$ at the start of the filter runs, particularly for shallow filters, the first headloss measurements were taken after 15 minutes into the filter run. Sampling points were positioned at the influent and effluent to each column. The influent turbidity was monitored by probes placed in the holding tank (Turbi-Tech 2000LS). The influent turbidity was adjusted to between 5 and 35 NTU using the online instrument for different filter runs by strategically positioning the suction pump in the discharge well to obtain different concentrations of solids in the holding tank. The filter was run at a constant flow rate of 25 $\mathrm{mh}^{-1}$ (the rate used in the full-scale unit); the tapered media size (running with a media gradient from large to small) enabled operation at higher hydraulic loading rate than typically used in depth filtration processes. Grab samples were collected on an hourly basis and were taken to laboratory for further analysis for TSS, turbidity and particle size. At the end of the 
filter cycle, the columns were backwashed individually by an air scour ( 2 minutes) followed by high rate $\left(60 \mathrm{mh}^{-1}\right)$ water wash $(10$ minutes $)$ using the filtrate.

\section{Laboratory Analysis of Filter Performance}

The total suspended solids (TSS) were determined on grab samples by gravimetric analysis Method 290D, 20 [19]. Turbidity was measured in the laboratory using a turbidity meter (2100 Lab Turb, Hach, US). The PSD of suspension particles was measured using a laser diffraction particle sizer (Spectrex PC-2200, Spectrex Corporation, California) within 10 minutes of sampling. The grab samples were diluted with distilled water by a factor proportional to the solid concentration to minimise the effect of shielding of particles by those on the same laser path, an effect which is more prevalent at high concentrations. Dilutions were chosen as x12 for turbidity $<15$ NTU, x18 for 15-20 NTU, x24 for 20-25 NTU and $x 30$ for 25-35 NTU to bring the particle concentration into the correct range for the particle sizing instrument.

\section{Filter Depth Modelling}

The Lawler and Nason [8] design criterion was based on empirical observations of filter performance and filter theory. Based on the Yao et al. [13] model the solution of the first order filtration relation for a packed bed is:

$$
C_{L}=C_{0} \exp (-\lambda L) \quad \text { and } \quad \lambda=\frac{3(1-\varepsilon) \eta \alpha}{2 d_{m}} \quad \text { Equation } 1
$$

where $\mathrm{C}_{0}$ and $\mathrm{C}_{\mathrm{L}}$ is the influent and effluent solid concentration in $\mathrm{mgL}^{-1}$ respectively, $\mathrm{L}$ is the filter of depth in $\mathrm{m}, \lambda$ is the filter coefficient in unit $\mathrm{m}^{-1}, \mathrm{~d}_{\mathrm{m}}$ is the media diameter in unit $\mathrm{m}$ and the dimensionless quantities, $\varepsilon$ is the filter bed porosity, $\alpha$ is the attachment efficiency and $\eta$ is the transport coefficient. Such semi-empirical models are widely used due to their 
relative simplicity and accuracy in estimating particle deposition in both natural and engineered filtration processes [22]. Lawler and Nason [8] designed the filter for $25 \%$ collection efficiency of 1-2 micron particles, therefore:

$$
1-\frac{C_{L}}{C_{0}}=1-\exp \left[-\frac{3}{2}(1-\varepsilon) \alpha \eta\left(\frac{L}{d_{m}}\right)\right]=0.25
$$

Equation 2

Such that

$$
\frac{3}{2}(1-\varepsilon) \alpha \eta\left(\frac{L}{d_{m}}\right)=\ln (0.75)=0.29
$$

Equation 3

The attachment efficiency $\alpha$ depends on the conditioning of the suspension (taken as 1 in this case) and the contact coefficient $\eta$ was calculated from the Tufenkji and Elimelech [14] model for a particle size of minimum removal $(\approx 1.5 \mu \mathrm{m})$, based on the media bed characteristics and applied filtration velocity. This approach utilised both a theoretical and empirical approach to determine the filter depth L based on media bed characteristics and Equation 3. In this work, the results are presented showing the empirically derived filter coefficients found from Equation 1, using the observed solids removal at each filter depth. These results were compared with the predicted filter co-efficient and filter depth from the Lawler and Nason criteria (equation 3).

\section{Results and Discussions}

\section{Impact of filter depth on performance}

This section presents the results and discussion of the effect of depth on the performance of filters of both single media and multimedia configurations. A single media anthracite filter is considered first followed by multimedia configurations of anthracite with flint, alumina and 
magnetite. The properties of the secondary wastewater influent for the filtration testing had the following characteristics: total suspended solids $25 \pm 2 \mathrm{mgL}^{-1}$, biological oxygen demand (BOD 5 ) of $13 \pm 3 \mathrm{mgL}^{-1}$ and a chemical oxygen demand (COD) of $83 \pm 8 \mathrm{mgL}^{-1}$.

\section{Anthracite single media filter}

The removal efficiency of the anthracite media filter improved as the filter media was made deeper (Figure 1a). However, the corresponding empirically derived filter coefficients for the filters were found to decrease from 5.6 to $1.8 \mathrm{~m}^{-1}$ as the filter depth increased from 0.02 to $0.42 \mathrm{~m}$ for filters operated at $25 \mathrm{mgL}^{-1} \mathrm{TSS}$ (Figure 1a). As the filter bed becomes deeper, the overall filter coefficient decreases exponentially, subsequently additional depth has proportionally less impact on solids removal. The filter coefficient dropped markedly in the first $0.10 \mathrm{~m}$ depth of the filter showing the high removal of solids that occurs in the top of the filter bed in single media filters such as the anthracite filter. This is in agreement with other researchers who have shown that solids removal was mainly concentrated in the top part of the filter $[3,15]$.

The filter coefficient calculated using the Lawler and Nason [8] design criterion (Equation 2 and 3) was also plotted for comparison (Figure 1a). The design criterion filter coefficient coincides with experimentally derived values at a depth near $0.1 \mathrm{~m}$, and was slightly higher for less deep filters and lower as the filter depth becomes greater than $0.1 \mathrm{~m}$. Thus, the design criterion implies a slight higher removal for shallow filters and lower removal at depth. The results of the present study indicate that that the wastewater solid particles penetrate the filter more and removal at depth is better than predicted by the Lawler and Nason [8] design criterion. These results suggest that some modification of the Lawler and Nason [8] formulation is needed through interrogation of the filter attachment efficiency and the transport mechanism assumptions. However, both the experimental results and the design 
criterion analysis show that the coefficients approach a constant. For the experimental data, this shows that above a depth of $0.1 \mathrm{~m}$, the filter depth would have to increase significantly to improve solids removal. For example, the filter depth would have to increase by four times from 0.1 to $0.4 \mathrm{~m}$ for the removal efficiency to double from $23 \%$ to $49 \%$. Therefore, the benefit of increasing filter depth diminishes as the filter becomes deeper. This is because, in single media filters, the media size increases with depth due to gravity stratification during the backwash, such that big media grains have less surface area for contact compared to the collective surface area of many small grains [23]. Additionally, reduction in particle concentration reduces the number of collision or contacts and hence the capture of particles. These results agree with previous work that has shown that single media filters generally over-utilise the top section of the filter for solids retention and under-utilise the rest of the filter depth for solid removal and storage [24-25].

The modelled filter depths using the rule-of-thumb guideline and the Lawler and Nason [8] design criterion are shown in Figurelb based on the anthracite media characteristics described above. Here, the anthracite filter would be designed at $1.1 \mathrm{~m}$ depth by the guideline and $0.96 \mathrm{~m}$ depth by Lawler and Nason [8] criterion for the filter operated at $25 \mathrm{mh}^{-1}$ hydraulic loading rate. Based on the rule-of-thumb guideline design, the filter would be designed deeper in comparison to the Lawler and Nason [8] criterion up to the hydraulic loading rate of $35 \mathrm{mh}^{-1}$, while Lawler and Nason [8] designs the filter deeper thereafter. The two design criterions coincided at $37 \mathrm{mh}^{-1}$ hydraulic loading rate, which is much higher than hydraulic loading rates typically used in practice. Thus, for all practical filtration rates, the rule-of-thumb guidelines filters are conservatively designed, hence liable to higher headloss. Deepening a filter moderates for loss in performance as hydraulic loading rate increases, however as the study shows, the depth needs to increase by four times to double solids removal with consequences on the headloss development (as discussed later in the paper). 
The regression fit of the observed turbidity removal with filter depth from Figure 1a yielded a relationship of: \% Removal $=79.238 \mathrm{~L}^{0.5302}\left(\mathrm{R}^{2}=0.97\right)$. Using this equation for a filter operated at $25 \mathrm{mh}^{-1}$ to extrapolate performance (Figure $1 \mathrm{~b}$ ), an anthracite filter of $1.1 \mathrm{~m}$ depth (rule-of -thumb guideline) would have a removal efficiency of $82 \%$ while at $0.96 \mathrm{~m}$ depth (the Lawler and Nason [8] design) would achieve 78\% removal efficiency. Both designs would achieve acceptable filter performance for tertiary wastewater filtration, where wellperforming wastewater filtration systems typically have removal efficiencies of about $75 \%$ or better [1]. This extrapolation shows that an anthracite filter of $0.9 \mathrm{~m}$ depth is needed to achieve $75 \%$ removal, thus a slightly lower depth than the Lawler and Nason [8] design depth. Many water and wastewater filters are gravity operated and typically operate at filtration rates around $5 \mathrm{mh}^{-1}$ [25]. Operating at this hydraulic loading rate would require a filter of $0.5 \mathrm{~m}$ depth using the Lawler and Nason [8] design criterion, while the rule-of-thumb guideline will still design the filter at $1.1 \mathrm{~m}$. The rule-of-thumb guidelines make no reference to the hydraulic loading rate while the Lawler and Nason [8] criterion does. Therefore, across a wide range of hydraulic loading rates, many filters designed using the rule-of-thumb guideline may be over-designed in depth.

While deeper filters achieve higher solids retention, there was a downside with respect to headloss development in comparison to shallow filters (Figure 1a and $2 \mathrm{~b}$ ). The headloss obtained by filters of different depth on filtering the same volume of wastewater, $170 \mathrm{~m}^{3} \mathrm{~m}^{-2}$ at a turbidity of $11.3 \pm 0.3 \mathrm{NTU}$ and a suspended solids concentration of $26.0 \pm 0.7 \mathrm{mg} / \mathrm{L}$, increased almost exponentially with filter depth over a 7-hour filter run (Figure 2b). The filter of $0.42 \mathrm{~m}$ depth developed a headloss of 1.04 Bar while $0.32 \mathrm{~m}$ filter depth developed a headloss of 0.40 Bar, and at $0.22 \mathrm{~m}$ depth a headloss of 0.13 Bar was developed (Figure $2 \mathrm{~b}$ ).

A deep filter may sometimes be desired to improve effluent quality as increasing the depth of the filter also increases the filter surface area hence improving the solids retention capacity of 
the filter. However, the rapid change in headloss as filters became deeper is a major constraint in their operation as the maximum pressure loss at full scale plants is usually quite limited. For example, for a filter at $0.42 \mathrm{~m}$ depth filter after processing $170 \mathrm{~m}^{3} \mathrm{~m}^{-2}$ wastewater, a headloss of 1.04 Bar was seen. This is equivalent to a water head of $10.6 \mathrm{~m}$, which is unlikely to be available on most sites at the tertiary treatment stage, where a water head of $3-5 \mathrm{~m}$ is typical $[15,25]$. Therefore, the filters would have to backwash on a regular basis. A pressure filter can solve the headloss limitation in this case enabling them to attain long filter runs before a terminal head is reached.

\section{Multimedia filters}

The single media anthracite filter had the lowest removal efficiency for equivalent depths of filter bed in comparison to multimedia configurations (Figure 3a). The filter performance improved with each additional media material. As an illustration, for filters of a combined depth of $0.24 \mathrm{~m}$ treating $170 \mathrm{~m}^{3} \mathrm{~m}^{-2}$, the anthracite single media filter, anthracite-flint dual media filter, anthracite-flint-alumina tri-media filter, and anthracite-flint-alumina-magnetite quadruple media filter had solids load retentions of $5.81 \mathrm{~g}, 8.63 \mathrm{~g}, 10.96 \mathrm{~g}$ and $11.33 \mathrm{~g}$ respectively (Figure 3a) resulting in specific mass deposits of $5.64 \mathrm{kgTSS} . \mathrm{m}^{-3}, 8.38 \mathrm{kgTSS} . \mathrm{m}^{-}$ ${ }^{3}, 10.64 \mathrm{kgTSS} . \mathrm{m}^{-3}$ and $11 \mathrm{kgTSS} . \mathrm{m}^{-3}$. A multimedia filter therefore does not need to be very deep to achieve significantly better effluent quality. Further evidence for this is shown for a quadruple filter operated at $25 \mathrm{mh}^{-1}$ where a $75 \%$ removal efficiency was achieved by a 0.40 $\mathrm{m}$ deep filter in comparison to $50 \%$ achieved by the same depth of a single media filter (Figure $3 \mathrm{~b}$ and Figure 1a).

The multimedia filter configurations developed comparable headloss to the single media anthracite filter despite them retaining more solids than the anthracite filter of equivalent depth (Figure 3b). The comparison of the single media anthracite filter to multimedia 
configurations show headlosses between 0.13-0.17 Bar, showing only small differences between the filters at $0.24 \mathrm{~m}$ depth (Figure $3 \mathrm{~b}$ ). The small difference in headloss development occurred despite the quadruple filter retaining almost double the mass of solids. Therefore, following 7 hours of filtration of $170 \mathrm{~m}^{3} \mathrm{~m}^{-2}$ volume of wastewater for the single media anthracite filter and quadruple filter, the solids retained were respectively 5.81 and $11.33 \mathrm{~g}$.

For quadruple filters of different depth, the headloss increased exponentially as the filters became deeper (Figure 4a). For example, the headloss after filtering $170 \mathrm{~m}^{3} \mathrm{~m}^{-2}$ ranged from 0.2 Bar for a $0.1 \mathrm{~m}$ depth filter to $1.3 \mathrm{Bar}$ for $1.7 \mathrm{~m}$ depth filter (Figure $4 \mathrm{a}$ ). In reaching the 1 Bar headloss, the quadruple filter retained $19.50 \mathrm{~g}$ after filtering $170 \mathrm{~m}^{3} \mathrm{~m}^{-2}$ of wastewater while the anthracite filter retained $9.54 \mathrm{~g}$ for the same volume treated and for the same influent concentration (Figure 2-4). Therefore, in addition to a superior solids retention in filters of multimedia configuration, additional media moderates headloss development such that the filter can be run with greater throughput.

The multimedia filters removed more particles compared to the single media filter. The characteristics of the particles in the effluent were also found to depend on the depth of the filter. A shallow filter such as at $0.24 \mathrm{~m}$ depth had large numbers of particles in the effluent ranging from 5-100 $\mu \mathrm{m}$ (Figure 4b). For example, there were 6045 particles $/ \mathrm{mL}$ between 5$15 \mu \mathrm{m}$ decreasing to 340 particles $/ \mathrm{mL}$ for $50-100 \mu \mathrm{m}$ (Figure $4 \mathrm{~b}$ ). For a deeper filter of 1.28 $m$ depth, fewer particles were seen in these size ranges. For example, there were 5093 particles $/ \mathrm{mL}$ in the $5-15 \mu \mathrm{m}$ range and only 47 particles $/ \mathrm{mL}$ in the $50-100 \mu \mathrm{m}$ range (Figure 4b). Thus, the particle size exiting the filter reduced as the filters got deeper. One apparent anomaly in the data obtained was for particles $<5 \mu \mathrm{m}$, where these sized particles were increasingly found as the filter increased in depth. These small particles were seen for filter depths of $0.48 \mathrm{~m}$ and above. Explanations for this can be ascribed to a combination of factors. Firstly, the potential for shielding of small particles by larger particles is increased at the 
higher particle concentrations. While sample dilution was carried out on these samples by a factor proportional to the solids concentration, this did not consider differences in the particle size distributions present in the samples. Secondly, at higher solids concentrations, small particles may aggregate into larger ones in the measuring cell due to increased opportunities for particle-particle collisions. Regardless of this, the deeper filters had more attachment sites hence the greater solids retention and improved removal of large particles, where the bulk of the solids mass lies, which was in good correlation to the solids removal efficiencies observed (Figure 3a).

\section{Impact of solids concentration on filter performance}

The retention of solids in the filter configurations were investigated at different influent concentrations to represent changes in the quality of the secondary effluent received by filtration processes from changes in hydraulic loading rate, clarifier performance and other operational parameters. The changes in solids retention with increasing influent concentration (Figure 5a), and the percentage solids removal (Figure 5b) have been illustrated for similar media bed depths of anthracite media and quadruple media filters.

An single media anthracite filter and a quadruple filter of $0.32 \mathrm{~m}$ depth were used as an illustration, with other filter depths showing similar observations. The anthracite filter of depth $0.32 \mathrm{~m}$ was found to have a solids load retention that increased from $0.79 \mathrm{gh}^{-1}$ to 2.52 $\mathrm{gh}^{-1}$ while the $\%$ solids removal decreased from $52 \%$ to $27 \%$ when the influent solids concentration increased from $13.1 \mathrm{mgL}^{-1}$ to $73.2 \mathrm{mgL}^{-1}$ respectively (Figure 5a and b). The anthracite filter coefficients were also found to decrease from $1.48 \mathrm{~m}^{-1}, 1.18 \mathrm{~m}^{-1}$ and $0.93 \mathrm{~m}^{-1}$ as the influent solids concentration increased from $25 \mathrm{mgL}^{-1}, 39 \mathrm{mgL}^{-1}$ and $53 \mathrm{mgL}^{-1}$ respectively. Thus, the filter effluent quality was seen to deteriorate when the influent 
concentration increased. In comparison to the single media anthracite filter, the quadruple media filter of a similar total depth had almost double the solids retention $\left(0.79\right.$ to $\left.1.45 \mathrm{gh}^{-1}\right)$ and one and a half times more percentage solids removal (52 to $77.4 \%$ ) compared to the anthracite filter of the same overall depth when filtering wastewater at a concentration of 13.1 $\mathrm{mgL}^{-1}$. The quadruple filter had the potential to retain more solids because of its tapered structure, where the media size decreases with depth unlike the single media anthracite filter where the media size increases slightly with depth. A decrease in media size with depth results in an increase in collector surface area with depth. This observation illustrated the improvement in solids retention that could be achieved by replacing a single media filter by a multimedia filter of the same total depth [12]. For both the anthracite and quadruple filter of $0.32 \mathrm{~m}$ depth, each suspended solid influent concentration increase of $10 \mathrm{mgL}^{-1}$ reduced the removal efficiency by an average factor of 0.9 while the solids retention increased by a factor of 1.2 .

A deep filter has a large collector surface area and hence may be affected differently by an increase in influent concentration. To illustrate, the impact of solids concentration was for a deeper filter of $1.28 \mathrm{~m}$ depth was shown (compared to the shallower $0.32 \mathrm{~m}$ filter shown previously in Figure 5). The solids load retention increased as the influent solids became more concentrated, changing from $1.18 \mathrm{gh}^{-1}$ to $7.15 \mathrm{gh}^{-1}$ as the influent concentration changed from $13.1 \mathrm{mgL}^{-1}$ to $73.2 \mathrm{mgL}^{-1}$ respectively (Figure 6a). However, unlike as was observed in the shallow filters of $0.32 \mathrm{~m}$ depth (Figure $5 \mathrm{~b}$ ), the percentage solids removal efficiency remained stable with increasing influent solids concentration (Figure 6b). This is also shown from analysis of the quadruple filter coefficient $(\lambda)$, which remained constant between 1.3-1.4 $\mathrm{m}^{-1}$ from 25 to $53 \mathrm{mgL}^{-1}$ influent solids concentration for quadruple filters operated at $25 \mathrm{mh}^{-}$ ${ }^{1}$ (Figure 6b). 
Wastewater treatment works are often challenged to meet discharge regulations despite the changing influent solids concentration, particularly at high solids concentrations.

Improvement in effluent quality can be achieved by either making the filter deeper or using multimedia filter configurations of equivalent depth in place of a single media filter [16]. A quadruple media filter was found to moderate the removal efficiency when the influent concentration increased, thus a high effluent quality can be maintained (Figure 6b).

Alternatively, to achieve high quality effluent standard, filters could be run in series, with an upstream roughing filter followed by a polishing filtration step since filters perform better at low concentrations as observed in this study (Figure 5a). The reasons for this being that at low solids concentration, there is a higher particle to collector ratio than at high concentrations hence increasing particle capture by collectors.

The filters also developed headloss at different rates when filtering wastewater influents of different concentrations. A filter of $0.48 \mathrm{~m}$ depth was chosen to illustrate the changes in headloss with influent concentration, with similar trends observed for other depths. The 0.48 $\mathrm{m}$ deep quadruple filter developed headloss gradually at $12.2 \mathrm{mgL}^{-1}$ influent concentration, but the increase was rapid at influent concentrations of $66.9 \mathrm{mgL}^{-1}$ (Figure $7 \mathrm{a}$ ). The solids retained by the filter per unit bed volume was determined as $3.4 \mathrm{kgm}^{-3}$ when the influent solids concentration was $12.2 \mathrm{mgL}^{-1}$ developing a headloss of 0.1 Bar for a filter run of 6.75 hours (Figure 7b). At an influent concentration of $66.9 \mathrm{mgL}^{-1}$, over the same filter run time, the solids retained per unit bed volume was $11.6 \mathrm{kgm}^{-3}$ developing a headloss of 1.7 Bar. The filter headloss increased with solids retention per unit filter volume with greater headloss developed for higher concentration influent solids because of greater solids retention [24, 25]. Consequently, at high influent solids concentration, while the solids load retention was good there was reduced throughput before the available head of the filter as reached. These results have shown that the quadruple media filter resulted in high levels of solids removal with low 
rates of headloss development. Further research is needed in order to assess the effects of intermixing between filter media layers following backwash, and the resulting impact on both particle removal and headloss.

\section{Conclusions}

The following conclusions were drawn from the study.

(a) The solids retention and removal efficiency was improved by making the filter deeper but headloss development becomes a limiting factor with increasing depth.

(b) Filters for wastewater filtration can be designed at lower depth than those using the commonly used design criteria to meet desired effluent quality since most of filter removal takes place close to the surface.

(c) Additional layers of filter materials from single, dual, triple to quadruple improved the filter performance for the same depth of filter bed.

(d) Filters of multimedia configuration developed headloss slower than single media filters of equivalent depth and retained more solids by distributing them throughout the depth of the filter.

(e) Increasing the influent concentration increased the solids retention while solids removal efficiency decreased for shallow filters. However, deepening the filter moderated the removal efficiency such that a stable efficiency was observed. 


\section{Acknowledgements}

The authors greatly thank Dr Garry Hoyland, Richard Hartnett and Dr Caroline Huo at

Bluewater Bio Ltd for funding and permitting the use of their patent technology to carry out this investigation. 


\section{References}

1. Hamoda, M. F., Al-Ghusain, I. and AL-Mutairi, N. Z. (2004) 'Sand filtration of wastewater for tertiary treatment and water reuse', Desalination, 164(3), pp. 203-211. doi: 10.1016/S0011-9164(04)00189-4.

2. Elfaki, H., Hawari, A. and Mulligan, C. (2015) 'Enhancement of multi-media filter performance using talc as a new filter aid material: Mechanistic study', Journal of Industrial and Engineering Chemistry, 24, pp. 71-78. doi: 10.1016/j.jiec.2014.09.010.

3. Yu, J., Li, Y., Liu, Z., Zhang, W. and Wang, D. (2015) 'Impact of loading rate and filter height on the retention factor in the model of total coliform (TC) removal in direct rapid sand filtration', Desalination and Water Treatment, 54(1), pp. 140-146. doi: $10.1080 / 19443994.2013 .879079$.

4. Tebbutt, T. H. Y. (1971) 'An investigation into tertiary treatment by rapid filtration', Water Research, 5(3), pp. 81-92. doi: 10.1016/0043-1354(71)90123-0.

5. West, J., Rachwal, A. J. and Cox, G. C. (1979) 'Experiences with high rate tertiary treatment filtration in the Thames Water Authority', Journal of the Institution of Water Engineers and Scientists, pp. 45-63. Available at:

http://www.scopus.com/inward/record.url?eid=2-s2.00018371832\&partnerID=tZOtx3y1.

6. Slavik, I., Jehmlich, A. and Uhl, W. (2013) 'Impact of backwashing procedures on deep bed filtration productivity in drinking water treatment', Water Research. Elsevier Ltd, 47(16), pp. 6348-6357. doi: 10.1016/j.watres.2013.08.009.

7. Montgomery, J. M. and Consulting Engineers Inc (1985) Water Treatment Principles and Design. New York: John Wiley \& Sons.

8. Lawler, D. F. and Nason, J. a. (2006) 'Granular media filtration: Old process, new thoughts', Water Science and Technology, 53(7), pp. 1-7. doi: 10.2166/wst.2006.201. 
9. French, D. (2012) 'Granular filter media: Evaluating filter bed depth to grain size ratio', Filtration + Separation. Elsevier Ltd, 49(5), pp. 34-36. doi: 10.1016/S00151882(12)70246-X.

10. Caliskaner, O., Tchobanoglous, G.,; Carolan, A. (1999) High-Rate Filtration with a Synthetic Compressible Media, Water Environment Research, 71, 6, 1171-1177.

11. Tang, H. L., Regan, J. M., Clark, S. E., Xie, Y. F. (2011) Prediction of Clean-bed Head Loss in Crumb Rubber Filters, ASCE Journal of Environmental Engineering, $137,55-62$.

12. Ncube, P., Pidou, M., Stephenson, T., Jefferson, B. and Jarvis, P. (2016) 'The effect of high hydraulic loading rate on the removal efficiency of a quadruple media filter for tertiary wastewater treatment', Water Research, 107, pp. 102-112. doi: 10.1016/j.watres.2016.10.060.

13. Yao, K., Habibian, M. T. and O’Melia, C. R. (1971) 'Water and Waste Water Filtration: Concepts and Applications', Environmental Science \& Technology, 5(11), pp. 1105-1112. doi: 10.1021/es60058a005.

14. Tufenkji, N. and Elimelech, M. (2004) 'Correlation Equation for Predicting SingleCollector Efficiency in Physicochemical Filtration in Saturated Porous Media', Environmental Science and Technology, 38(2), pp. 529-536. doi: 10.1021/es034049r.

15. Boller, M. a. and Kavanaugh, M. C. (1995) 'Particle characteristics and headloss increase in granular media filtration', Water Research, 29(4), pp. 1139-1149. doi: $10.1016 / 0043-1354(94) 00256-7$.

16. Horan, N. J. and Lowe, M. (2007) 'Full-scale trials of recycled glass as tertiary filter medium for wastewater treatment', Water Research, 41(1), pp. 253-259. doi: 10.1016/j.watres.2006.08.028.

17. Dawda, M., Davidson, M. and Middlebrooks, J. (1978) 'Granular media filtration of 
secondary effluent', Journal (Water Pollution Control Federation) , 50(9), pp. 21432156.

18. Holtz, R., Kovacs, W. D., Sheahan, T. C., (2010) An Introduction to Geotechnical Engineering (2nd Edition), Pearson, ISBN-13: 978-0132496346

19. APHA, AWWA and WEF (2005) Standard Methods for the Examination of Water and Wastewater. 21st edn, American Public Works Association. 21st edn. Washington D.C.

20. Wadell, H. (1935) Volume, Shape and Roundness of Quartz Particles, The Journal of Geology, 43(3), pp. 250-280.

21. Logsdon, G. S. (2008) Water Filtration Practices: Including Slow Sand Filters and Precoat Filtration. American Water Works Association, Denver, USA.

22. Jin, C., Zhao, W., Normani, S. D., Zhao, P., Emelko, M. B. (2017). Synergies of media surface roughness and ionic strength on particle deposition during filtration Water Research, 114, 286-295.

23. Howe, K. J., Hand, D. W., Crittenden, J. C., Trussell, R. R., Tchobanoglous, G. (2012) Principles of Water Treatment. John Wiley and Sons, New York.

24. Veerapaneni, S. and Wiesner, M. R. (1997) 'Deposit Morphology and Head Loss Development in Porous Media', Environmental Science \& Technology. ACS, 31(10), pp. 2738-2744. doi: 10.1021/es960979h.

25. Williams, G. J., Sheikh, B., Holden, R. B., Kouretas, T. J. and Nelson, K. L. (2007) 'The impact of increased loading rate on granular media, rapid depth filtration of wastewater', Water Research, 41(19), pp. 4535-4545. doi: 10.1016/j.watres.2007.06.018. 